\title{
Absorption, Fluorescence, Photochemical and Thermal cis/trans Isomerization Reactivity of 1-Methyl-4-(4'-aminostyryl)pyridinium Iodide
}

\author{
FARAG M A ALTALBAWY* and EL-SAYED A M AL-SHERBINI
}

Department of Measurements and Environmental Applications, National Institute of Laser Enhanced Sciences (NILES), University of Cairo, Giza, 12613, Egypt

f_altalbawy@yahoo.com

Received 19 July 2015 / Accepted 31 July 2015

\begin{abstract}
The photo and thermal cis/trans isomerization reactions are studied for 1-methyl-4-(4'aminostyryl)pyridinium iodide, $\mathrm{Cy}$, which is prepared in the trans form. In a basic solution the trans form, $\mathrm{Cy}_{\mathrm{tr}}$, cannot isomerise directly to the cis form. Its protonated form, $\mathrm{Cy}_{\mathrm{tr}} \mathrm{H}^{+}$, is active and reacts photochemically from trans to cis configuration, $\mathrm{Cy}_{\mathrm{c}} \mathrm{H}^{+}$. The quantum yields $\Phi_{\mathrm{tc}}$ and $\Phi_{\mathrm{ct}}$ are determined in water. Deprotonation process of $\mathrm{Cy}_{\mathrm{c}} \mathrm{H}^{+}$yields the cis isomer, $\mathrm{Cy}_{\mathrm{c}}$, which can thermally back to the stable trans form. The rate constants and the activated parameters of the thermal reaction are determined. Due to irreversibility of the thermal reaction, a complete molecular reaction cycle is performed in one direction. To get more information on the spectral characteristics of protonated form, the photochromic of the title compound is studied in different fourteen solvents. The linear relationships between absorption energy with hydrogen bond acceptor ability of the solvents and fluorescence energy of $\mathrm{CyH}^{+}$with free energy for transferring the proton to the solvent, $\mathrm{DG}_{\mathrm{t}}^{\mathrm{o}}$ were determined.
\end{abstract}

Keywords: Styryl pyridinium cyanine dye, Photochemical and thermal trans/cis isomerization, Photochromism

\section{Introduction}

Styryl dyes are known as heterocyclic organic molecules of the general formula $\mathrm{R}-\mathrm{Het}^{+}-\mathrm{CH}=\mathrm{CH}-\mathrm{ArX}^{-}$can undergo $\mathrm{E}-\mathrm{Z}$ photo-isomerization, electrocyclization and $[2+2]$ Cycloaddition photoreactions owing to the presence of ethylene bonds in the dye molecules $^{1-5}$. The photochemical properties of styryl dyes have been extensively studied ${ }^{6-12}$; owing to their applications in several areas. These compounds were originally utilized as sensitizing additives to photographic emulsions and other additives in photographic industry, but their unique structural and photophysical characteristics have since proven useful for a wide variety of other applications requiring photosensitive materials, such as optical recording media and solar cells ${ }^{13-16}$. These materials also represent an important group of 
biologically active compounds and are widely applied in the pharmaceutical industry ${ }^{17}$. In recent years, interest in the application of styrylcyanines as novel and successful fluorescent probes in numerous bioanalytical methods has grown especially in RNA and DNA analyses ${ }^{18-22}$. On the other hand cyanine dyes are well known as solvatochromic and photoreactive compounds ${ }^{23}$. Due to these properties they are potentially useful in many areas such as solar energy ${ }^{24,25}$, photodynamictherapy ${ }^{26}$, photosensitizers $^{27}$, in laser doublers ${ }^{28}$. Merocyanine dyes are also used as an electrochromic molecular probe to measure the membrane potentials with high voltage sensitivity ${ }^{29,30}$. The molecular structure of a typical styrylcyanine dye, 1-methyl-4-(4-aminostyryl)pyridinium iodide (Cy), has two mesomeric structures, the quinonoid form $\mathrm{Cy}_{\mathrm{q}}$ and the benzenoid form $\mathrm{Cy}_{\mathrm{b}}$ (Scheme 1$)^{31}$.

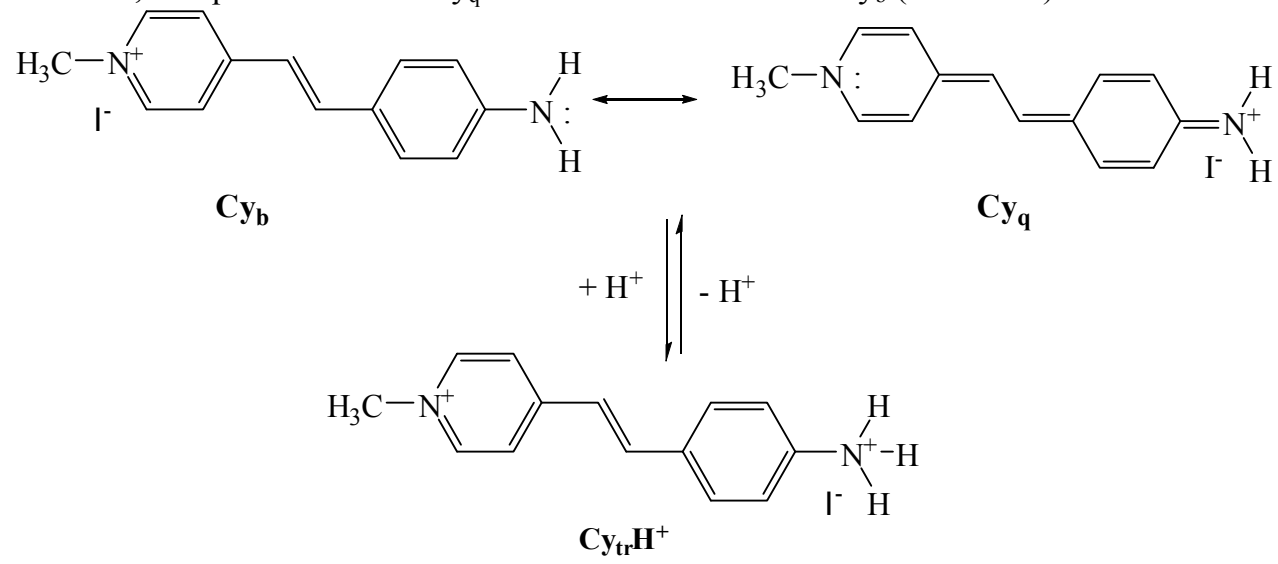

Scheme 1. The tautomerism of 1-methyl-4-(4'-aminostyryl)pyridinium iodide

Photochromic studies were carried out on $\mathrm{Cy}$ in different solvents ${ }^{31,32}$. The hypsochromic band shift of the longest absorption band is indicative of the dipolemoment decreasing up on electronic excitation and this shift was found to be greater than the bathochromic shift of the fluorescence band, which was observed concomitant with a decrease of the Stokes shift as the solvent polarity decreases. Also, absence of the effect of hydrogen bonding on the absorption and fluorescence shifts of Cy strengthens the effect of the intramolecular charge transfer on its spectral shifts ${ }^{31}$. Protonation process of $\mathrm{Cy}_{\mathrm{tr}}$ represents a limiting case of the quinonoid and benzenoid resonance, with a predominant benzenoid contribution, (Scheme 2). The photochemically trans/cis isomerization is one of the most important processes in photochemical and photobiological reactions. On the other hand, no information has concerned the chemical reactivity of the $\mathrm{Cy}_{\mathrm{tr}} \mathrm{H}^{+}$structure and its absorption and florescence spectra. Also, not enough studies have been reported for the activity of cis form in the literatures, except for the papers of Williams et al., who reported spectroscopic detection of cis and trans isomers on the bishydrochlorides and methiodidehydrochlorides of some 4 -amino-2-styrylpyridines by UV irradiation in aqueous and $50 \%(\mathrm{v} / \mathrm{v}) \mathrm{MeOH}-\mathrm{H}_{2} \mathrm{O}$ solutions ${ }^{32,33}$. Behera et al. synthesized the cis isomer of the hemicyanine dye by a novel method using $\mathrm{Ag}_{2} \mathrm{O}$ as a catalyst ${ }^{34,35}$. In view of these observations and in continuation of our previous work directed to the synthesis of novel heterocyclic compounds and study its isomerization and tautomerism ${ }^{12,31,36-43}$, we reported here a facile methods for the applied the physical constraints approach on the photochemical and thermal isomerization reactivity for the protonated and unprotonated forms, which hitherto unreported in cis form and have been known only in the trans form. 


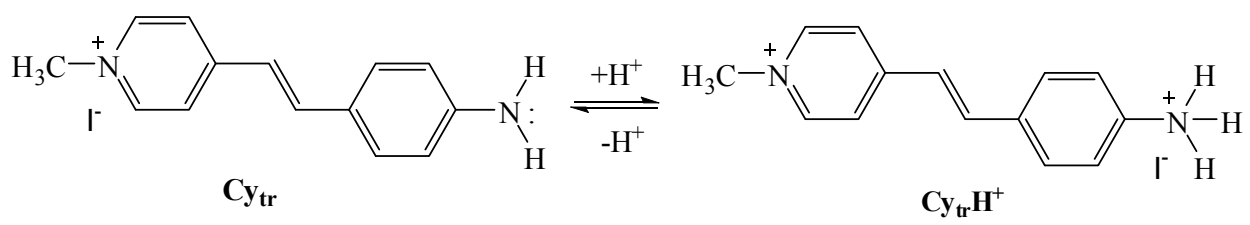

Scheme 2. Protolytic forms of 1-methyl-4-(4'-aminostyryl)pyridinium iodide

\section{Experimental}

1-Methyl-4-(4'-aminostyryl)pyridinium iodide was synthesized according to procedures described in literature ${ }^{31,43}$ as follows: $p$-amino benzaldhyed $(1.21 \mathrm{~g}, 10 \mathrm{mmol})$ dissolved in a minimum amount of absolute ethanol, was added drop wise to $(2.35 \mathrm{~g}, 10 \mathrm{mmol})$ of 1-methylpicolinium iodide dissolved in $25 \mathrm{~mL}$ of absolute ethanol was added piperdine $(1.5 \mathrm{~mL}, 10 \mathrm{mmol})$. The reaction mixture was stirred for $20 \mathrm{~h}$ at room temperature and then refluxed for $30 \mathrm{~min}$. The resulting solution was cooled to room temperature and the light brown precipitate was filtered off, washed with cold water, deride and recrystalized several times from distilled water. The melting points was determined and founded to be $278-280{ }^{\circ} \mathrm{C}$, of 1-methyl-4-(4-aminostyryl)pyridinium iodide, (Cy) (Scheme 1).

\section{Apparatus and experimental conditions}

The electronic absorption spectra were recorded on a Perkin-Elmer lambda 17 spectrophotometer by using a cuvette of $1 \mathrm{~cm}$ path length and a cuvette holder equipped for variable temperatures thermostated by using Julbo Thermo-Bath-U3. The fluorescence spectra measurements were recorded on a Shimadzu RF-5000 spectrofluorometer by using a cell of $1 \mathrm{~cm}$ path length and a cuvette holder equipped for variable temperatures thermostated by using thermobath TB- 85 . Fluorescence intensity was measured at right angle to the exciting light. A $5 \mathrm{mmol} \mathrm{dm}^{-3}$ stock solution of the dye in methanol was prepared and diluted to $30 \mu \mathrm{mol} \mathrm{dm}{ }^{-3}$. Acidic solution was prepared by adding $10 \mathrm{mmol} \mathrm{dm}{ }^{-3} \mathrm{HCl}$. Basic

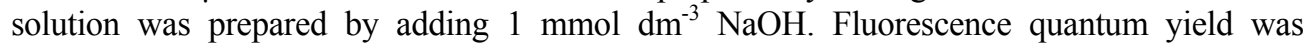
determined by comparing the fluorescence intensity of the solution with a reference solution. Narrow excitation slits were used in order to maintain the photo-isomerization reaction at a low rate. Quinine sulphate dissolved in $(1 \mathrm{~N}) \mathrm{H}_{2} \mathrm{SO}_{4}$ was an appropriate solution as spectral and fluorescence reference with of $\Phi_{f}^{r}=0.55, \lambda_{\mathrm{ex}}=366 \mathrm{~nm}$. Also, flourescien dye dissolved in $0.1 \mathrm{~mol} \mathrm{dm}^{-3} \mathrm{NaOH}$ was selected as spectral and fluorescence reference for the basic structure with $\Phi_{f}^{r}=0.9$ at $\lambda_{\mathrm{ex}}=450 \mathrm{~nm}^{44}$. The $\Phi_{f}^{s}$ value was calculated by using the equation (1):

$$
\Phi_{f}^{s}=\Phi_{f}^{r}\left(\int \mathrm{I}_{\mathrm{s}}(\mathrm{d} v \dot{)}) \mathrm{A}_{\mathrm{r}} \mathrm{n}_{\mathrm{s}}^{2}\right) /\left(\int \mathrm{I}_{\mathrm{r}}\left(\mathrm{d}{ }^{2}\right) \mathrm{A}_{\mathrm{s}} \mathrm{n}_{\mathrm{r}}^{2}\right)
$$

Where $\Phi_{f}^{s}$ and $\Phi_{f}^{r}$ are the fluorescence quantum yields for the substance under investigation and the reference, respectively. Integrals over $I_{S}$ and $I_{r}$ are the areas under the corrected emission spectra. $A_{s}$ and $A_{r}$ are the absorbance values for the substance and the reference. $n_{s}$ and $n_{r}$ are the refractive index for solvent used and for the solvent of the reference.

The quantum yields of the photochemical trans/cis and cis/trans isomerization reactions $\left(\Phi_{\mathrm{tc}}\right.$ and $\left.\Phi_{\mathrm{ct}}\right)$ were carried out in the quantum yield reactor OYR-20 from applied photophysics limited at $366 \mathrm{~nm}$. The samples were irradiated in cuvette of $1 \mathrm{~cm}$ path length and $3 \mathrm{~cm}^{3}$ volume, connected to a thermostat. The absorption spectrophotometer was used 
for recording the absorption spectra at different stages of photoreaction. The intensity of the absorbed light, $\mathrm{I}_{\mathrm{o}}$, was measured by using a potassium ferrioxalate actinometer and the Hatchard and Parker method ${ }^{45,46}$. Gauglitz's method was applied for determining the quantum $^{47-50}$ yields $\Phi_{\mathrm{tc}}$ and $\Phi_{\mathrm{ct}}$. Equation (2) was used by Gauglitz to determine the pseudo total quantum yield $Q$ by measuring the absorbance $E$ at time $t$ in the presence of light flux $I_{0}$.

$$
\mathrm{I}_{0}=\frac{1}{-Q\left(t_{1}-t_{2}\right)}\left(\left[\frac{F\left(E_{1}\right)\left(E_{2}-E_{\infty}\right)-F\left(E_{2}\right)\left(E 1-E_{\infty}\right)}{E_{2}-E_{1}} \ln \frac{E_{1}-E_{\infty}}{E_{2}-E_{\infty}}\right]+F\left(E_{1}\right)-F\left(E_{2}\right)\right)
$$

Where $\mathrm{E}_{\mathrm{N}}$ is the absorbance of the photo-stationary state at time $\mathrm{N}$ and also $\mathrm{E}_{1}$ and $\mathrm{E}_{2}$ are at $t_{1}$ and $t_{2}$, respectively. $F(E)$ is the photo kinetic factor, equation (3):

$$
\mathrm{F}(\mathrm{E})=\frac{1}{-Q\left(t_{1}-t_{2}\right)} \mathrm{E} /\left(1-10^{-\mathrm{E}}\right)
$$

The pseudo total quantum yield $\mathrm{Q}$, which is independent of time and concentration, was determined using several absorbance values at different times of irradiation, yielding the corresponding values of $\Phi_{\mathrm{tc}}$ and $\Phi_{\mathrm{ct}}$, equation (4):

$$
\mathrm{Q}=1000\left(\Phi_{\mathrm{tc}} \varepsilon_{\mathrm{tr}}+\Phi_{\mathrm{ct}} \varepsilon_{\mathrm{c}}\right)
$$

Where $\varepsilon_{\mathrm{tr}}$ and $\varepsilon_{\mathrm{c}}$ are the molar extinction coefficients for pure trans and cis forms, respectively. The Blanc and Ross method ${ }^{51}$ was used after modification to calculate the molar extinction coefficient of the cis, $\varepsilon_{\mathrm{c}}$. This method can be applied to a mixture of two isomers, only one of which exhibits fluorescence and allows one to determine the absolute absorption spectrum of the non-fluorescing isomer by comparing the fluorescence intensities of two solutions different in their optical densities. Since the geometrical factor is different for the two samples, which have different optical densities, in the developed method the fluorescence intensities of the two samples with different total concentrations of the isomers, but with equal optical densities D at the excitation wave length, are compared. Equation (5) was used for determining the molar extinction coefficient of cis isomer at the excitation wave length, $\varepsilon_{\mathrm{c}}$.

$$
\varepsilon_{\mathrm{c}}=\frac{I_{f_{1}}-I_{f 2}}{C_{2} I_{f_{1}}-C_{1} I_{f_{2}}} \times \frac{D}{d}
$$

Where $I_{f 1}$ and $I_{f 2}$ are fluorescence intensities of $c_{1}$ and $c_{2}$ concentrations and $d$ is the optical path length of the cuvette. In this work $5 \mathrm{mmol} \mathrm{dm}^{-3}$ stock solution of the dye in

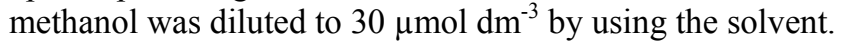

Thermally cis/trance isomerization was studied as; the concentration of the (Cy) was $30 \mu \mathrm{mol} \mathrm{dm}{ }^{-3}$ was prepared in $50 \%$ ethanol solution which is very slightly acidified using $10 \mathrm{mmol} \mathrm{dm}^{-3} \mathrm{HCl}$, this was found to be enough for the $(\mathrm{Cy})$ to react photochemically under the effect of irradiation at $366 \mathrm{~nm}$ to give the protonated cis form. The cuvette was irradiated for 30 minutes. The thermal reaction was followed immediately spectrophotometrically at $449 \mathrm{~nm}$ after addition of one drop of $1.0 \mathrm{~N} \mathrm{NaOH}(\mathrm{pH}=10)$. The first order rate constant of cis/trans isomerization was measured at different temperatures to determine the activation parameters.

\section{Results and Discussion}

\section{Spectroscopic and protolytic properties}

In aqueous basic solution the absorption spectrum of $30 \mu \mathrm{mol} \mathrm{dm}{ }^{-3}$ of unprotonated $\left(\mathrm{Cy}_{\mathrm{tr}}\right)$, exhibits the longest intramolecular charge transfer band at $400 \mathrm{~nm}$ with molar extinction 
coefficient, $\varepsilon_{\max }=26.6\left(10^{3} \mathrm{dm}^{3} \mathrm{~mol}^{-1} \mathrm{~cm}^{-1}\right)$. The fluorescence spectrum of $\mathrm{Cy}_{\mathrm{tr}}$ exhibits a fluorescence band at $537 \mathrm{~nm}$ when the solution is excited at $\lambda_{\mathrm{ex}}=400 \mathrm{~nm}$. Absorption and fluorescence band maxima change up on protonation from 400 and 537 to 325 and $430 \mathrm{~nm}$, respectively, (Figure 1). Also, this process changes the fluorescence yield, $\Phi_{\mathrm{f}}$, from 0.070 to 0.043. In pure basic solution, the absorbance of unprotonated $\mathrm{Cy}_{\mathrm{tr}}$ did not change after irradiation for $15 \mathrm{~min}$. Therefore, $\mathrm{Cy}_{\mathrm{tr}}$ could be considered as a photochemical inactive dye. On the other hand, absorption spectrum of the protonated structure, $\mathrm{Cy}_{\mathrm{tr}} \mathrm{H}^{+}$, was unstable and the absorbance of the longest wave length band decreases even under the room light.

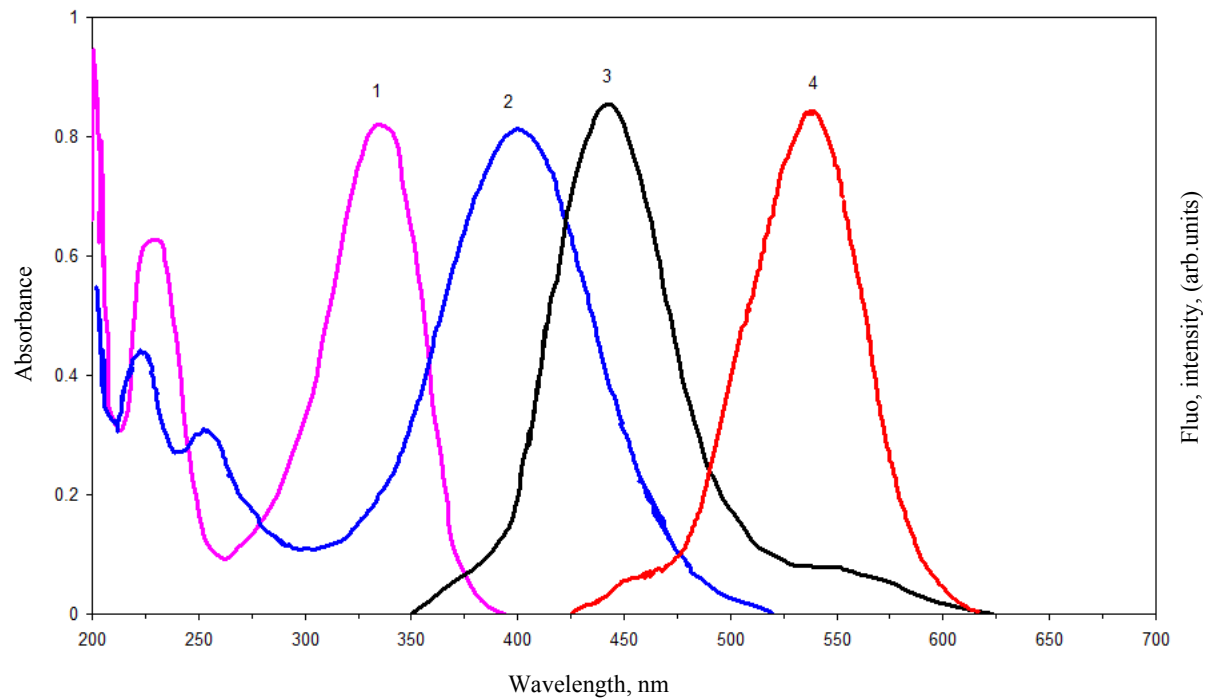

Figure 1. Excitation and emission spectra of $30 \mu \mathrm{mol} \mathrm{dm} \mathrm{dm}^{-3}$ aqueous solution for 1-methyl-4(4-aminostyryl)pyridinium iodide in both acidic and basic forms. (1) Absorption spectrum of $\mathrm{CyH}^{+},(2)$ absorption spectrum of $\mathrm{Cy}$, (3) fluorescence spectrum of $\mathrm{CyH}^{+}, \lambda_{\text {ex }}=325 \mathrm{~nm}$ and (4) fluorescence spectrum of $\mathrm{Cy}, \lambda_{\mathrm{ex}}=400 \mathrm{~nm}$

Therefore the absorption spectrum was recorded in the dark to avoid its photoreactivity. Absorption spectra of pure protonated trans $\mathrm{Cy}_{\mathrm{tr}} \mathrm{H}^{+}$and its photostationary state are shown in Figure 2.

The $\mathrm{pk}_{\mathrm{a}}$ of the dye was determined spectrophotometrically by measuring the absorption spectrum in different buffer solutions. Due to the presence of simple protolytic equilibrium between $\mathrm{Cy}_{\mathrm{tr}} \mathrm{H}^{+}$and $\mathrm{Cy}_{\mathrm{tr}}$ forms, sharp isosbestic points could be obtained after measuring the solutions only in the dark. The $\mathrm{pk}_{\mathrm{a}}$ and $\mathrm{pk}_{\mathrm{a}}{ }^{*}$ values in ground and excited state were calculated as 3.35 and 0.62 , respectively at $25^{\circ} \mathrm{C}$.

\section{Molecular reaction cycle}

The dipolar properties of unprotonated $\mathrm{Cy}_{\mathrm{tr}}$ and protonated $\mathrm{Cy}_{\mathrm{tr}} \mathrm{H}^{+}$structures are different in their positive charges and it is interesting to compare their physical and chemical reactivity. The whole skeleton of protonated $\mathrm{Cy}_{\mathrm{tr}} \mathrm{H}^{+}$in the ground state shows that the total charges equal $+2.0 \mathrm{e}$ and the distribution of the added charges as a result of protonation is mostly distributed over the aniline and the bridge moieties with a little extent over the pyridinium moiety. The molecular structure of $\mathrm{Cy}_{\mathrm{tr}} \mathrm{H}^{+}$represents an essentially stilbene-analogous structure, with two benzenoid rings and an ethylenic $\mathrm{C}=\mathrm{C}$ double bond, offering the possibility of cis/trans isomerism known for many stilbene derivatives. 


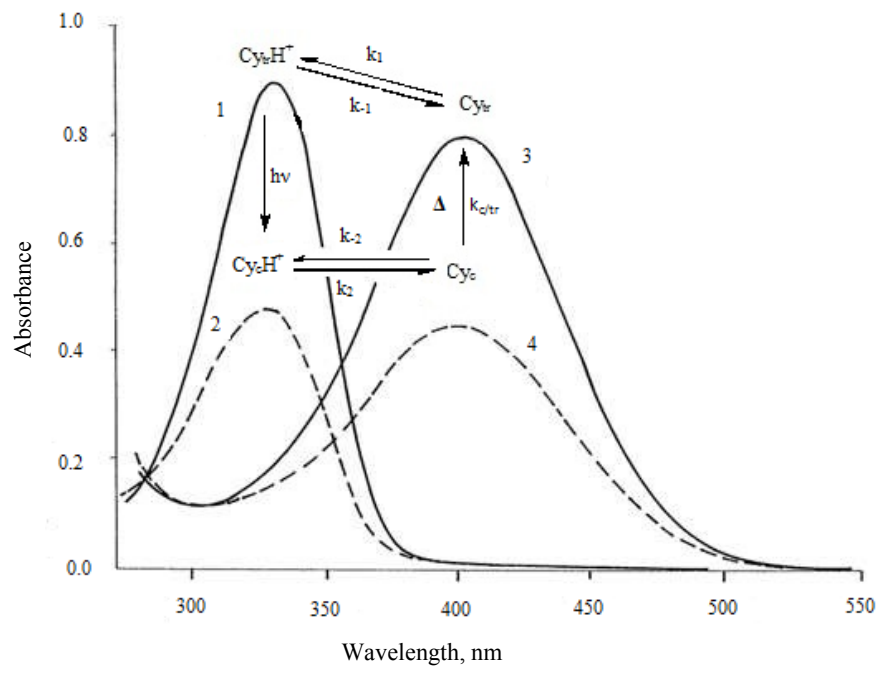

Figure 2. Absorption spectra representing the four stages of the reaction cycle (1) Absorption spectra of $30 \mu \mathrm{mol} \mathrm{dm} \mathrm{dm}^{-3}$ of pure protonated trans isomer $\left(100 \% \mathrm{CyH}^{+} \mathrm{tr}\right)$ in aqueous solution, (2) photo-stationary state $\left(\mathrm{CyH}_{\mathrm{c}}^{+}+\mathrm{CyH}_{\mathrm{tr}}^{+}, 64: 36\right)$ mixture obtained after irradiation of $\mathrm{CyH}_{\text {tr }}^{+}$at $366 \mathrm{~nm}$ and (3) Absorption spectra of $30 \mu \mathrm{mol} \mathrm{dm}{ }^{-3}$ of pure trans isomer $\left(100 \% \mathrm{Cy}_{\mathrm{tr}}\right)$ in aqueous solution and (4) spectrum of a 64:36 $\mathrm{Cy}_{\mathrm{c}} / \mathrm{Cy}_{\mathrm{t}}$ mixture obtained after addition of 1 drop of conc. $\mathrm{NaOH}$ on the photo-stationary state mixture solution

A $30 \mu \mathrm{mol} \mathrm{dm} \mathrm{dm}^{-3}$ aqueous solution of $\mathrm{Cy}_{\mathrm{tr}}$, prepared in the dark, was protonated by adding $1 \mathrm{mmol} \mathrm{dm}^{-3} \mathrm{HCl}$. Irradiation of $\mathrm{CytrH}^{+}$with $366 \mathrm{~nm}$ was performed and the progress of the reaction was followed by measuring the absorbance at different stages of the radiation until reaching the photo-stationary state (Figures 3 and 4). $\mathrm{Cy}_{\mathrm{c}} \mathrm{H}^{+}$could not be achieved thermally as cis/trans isomerization in aqueous solution.

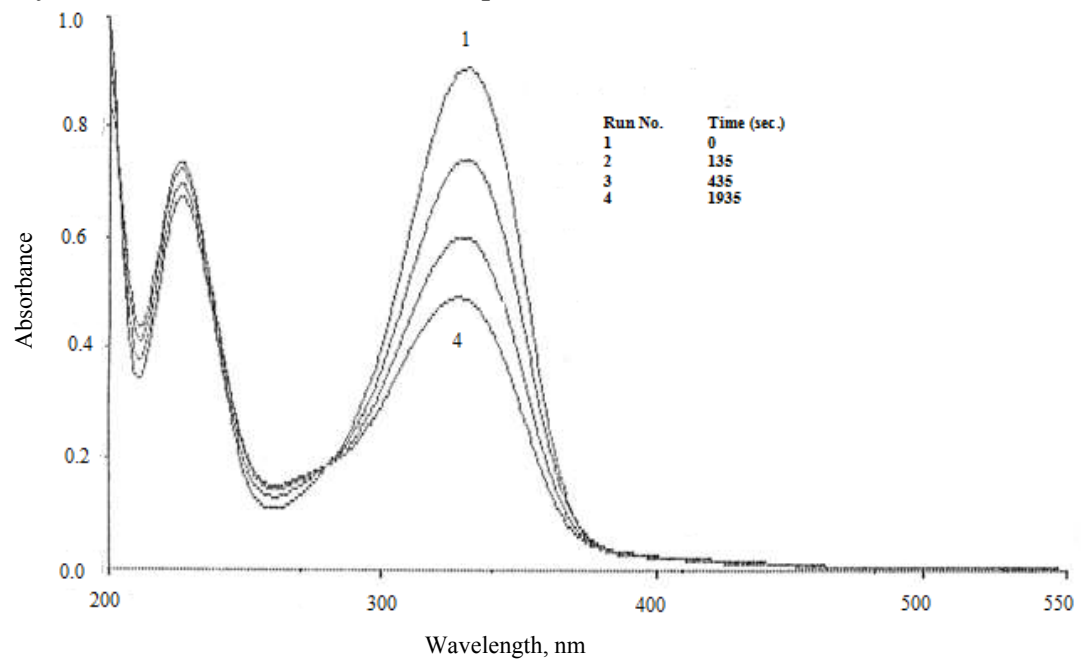

Figure 3. Absorption spectra of $30 \mu \mathrm{mol} \mathrm{dm} \mathrm{dm}^{-3}$ of pure protonated trans isomer $(100 \%$ $\left.\mathrm{CyH}_{\text {tr }}^{+}\right)$in aqueous solution at different irradiation times $\left(\lambda_{\text {irr }}=366 \mathrm{~nm}\right)$ 


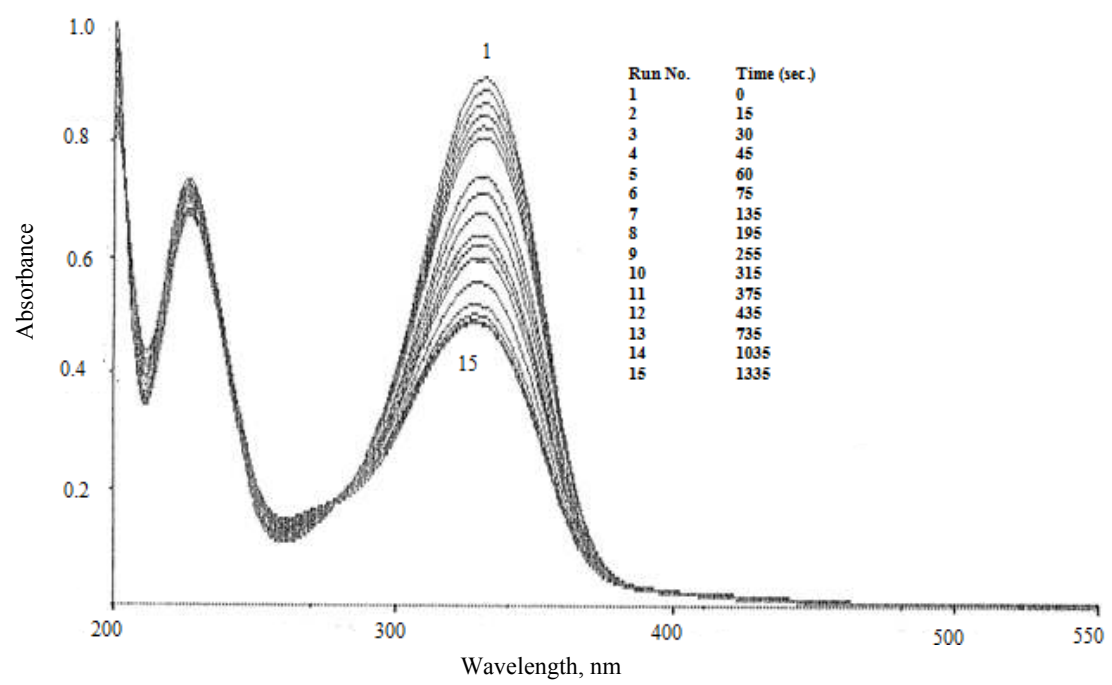

Figure 4. Absorption spectra of $30 \mu \mathrm{mol} \mathrm{dm} \mathrm{dm}^{-3}$ of pure protonated trans isomer $(100 \%$ $\left.\mathrm{CyH}^{+}{ }_{\text {tr }}\right)$ in aqueous medium at different irradiation times $\left(\lambda_{\text {irr }}=366 \mathrm{~nm}\right)$

Addition of 1drop of $1 \mathrm{~N} \mathrm{NaOH}$ to the cuvette of the solution at photo-stationary state converts the irradiated molecules $\mathrm{Cy}_{\mathrm{c}} \mathrm{H}^{+}$to the basic cis structure, $\mathrm{Cy}_{\mathrm{c}}$, which completely reverts thermally to the initial trans isomer form, $\mathrm{Cy}_{\text {tr }}$, Figure 2. The spontaneous thermal reaction proceeds as a first order reaction and the progress of the reaction was followed and measured spectrophotometrically.

The protolytic, photochemical and thermal reactions represent a complete molecular reaction cycle (Scheme 3).

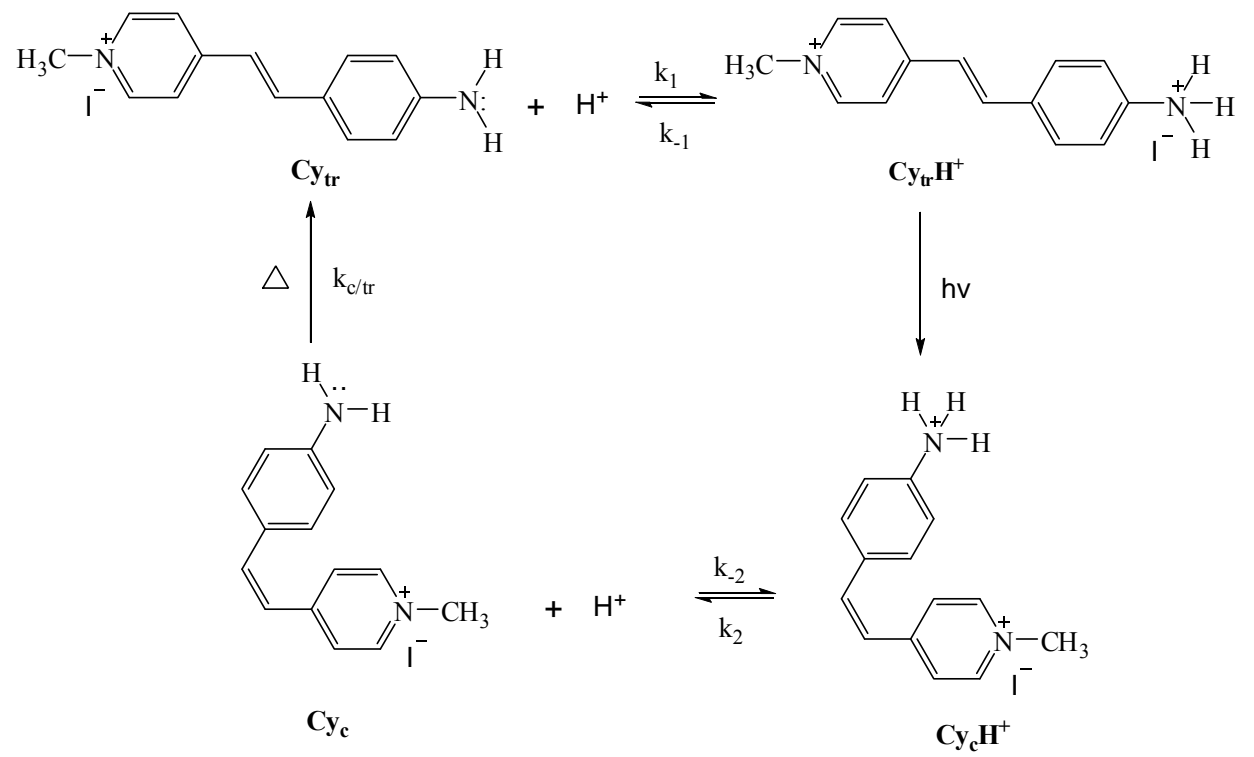

Scheme 3. The possible isomeric and protolytic forms 1-methyl-4-(4-aminostyryl) pyridinium iodide 
To get information on the photoreaction, the quantum yields of both trans $\rightarrow$ cis and cis $\rightarrow$ trans reactions are determined. For this, the spectra of pure trans and at photostationary state are recorded. The fraction of cis compound at photo-stationary state was calculated $(\alpha=0.64)$ by comparing its fluorescence intensity with a pure trans form. The modified Blanc and Ross method was used to determine the molar extinction coefficient value of the pure cis structure, $\varepsilon_{\mathrm{c}}\left(20.47 \times 10^{3} \mathrm{~L} \mathrm{~mol}^{-1} \mathrm{~cm}^{-1}\right)$, and used to calculate the spectrum of pure cis form, (Figure 2). The intensity of the absorbed light, $\mathrm{I}_{\mathrm{o}}$, was measured $\left(5.3 \times 10^{-10} \mathrm{E} / \mathrm{cm}^{2} \mathrm{~s}\right)$. By measuring the absorbance at different times of irradiation, the individual quantum yields $\Phi_{\mathrm{tc}}$ and $\Phi_{\mathrm{ct}}$ were determined as 0.61 and 0.49 , respectively ${ }^{31}$.

The photochemical behavior of $\mathrm{CyH}^{+}$as it is in good agreement with those reported for similar and with other structurally related compounds like stilbene, 1,2-diphenylpropylene, 4-stilbazole and Brooker's merocyanine dye, 1-methyl-4-(4-hydroxystyryl)pyridinium betaine, $\mathrm{MH}^{+}$(Table 1).

Table 1. The photochemical and photophysical data for $\mathrm{CyH}^{+}$and its similar compounds

\begin{tabular}{|c|c|c|c|}
\hline Compounds & $\Phi_{\mathrm{tc}}$ & $\Phi_{\mathrm{ct}}$ & $\Phi_{\mathrm{f}}$ \\
\hline Stilbene $^{52}$ & 0.50 & 0.35 & 0.039 \\
\hline 1,2-Diphenylpropene ${ }^{53}$ & 0.54 & 0.44 & \\
\hline 4-Stilbazole ${ }^{54}$ & 0.44 & 0.25 & 0.003 \\
\hline $\mathrm{CyH}^{+}$ & 0.61 & 0.49 & \\
\hline $\mathrm{MH}^{+55}$ & 0.33 & 0.57 & 0.015 \\
\hline $\begin{array}{l}\text { 1-Methyl-4'-( } p \text { - } N, N \text {-dimethyl- } \\
\text { aminostyryl)pyridinium iodide }{ }^{56}\end{array}$ & 0.255 & 0.47 & 0.007 \\
\hline 4-Nitro-4 -methoxy stilbene ${ }^{57}$ & 0.07 & 0.48 & \\
\hline
\end{tabular}

The comparison suggests that stilbene, stilbene like-structures and $\mathrm{CyH}^{+}$have nearly the same behavior, where the $\Phi_{\text {tc }}$ value is higher than $\Phi_{\text {ct }}$. By suggesting that there is analogy between 1,2-diphenylpropene, stilbene dyes and our compound cyanine dye, the photoisomerization of $\mathrm{Cy}_{\mathrm{tr}} \mathrm{H}^{+}$to $\mathrm{Cy}_{\mathrm{c}} \mathrm{H}^{+}$and vice versa may proceed via a phantom state $\mathrm{X}$, which is a common intermediate in the radiationless deactivation of both trans and the cis excited singlet states ${ }^{58}$. $\Phi_{\mathrm{tX}}$ can be determined by equation $(6)^{59}$ :

$$
\Phi_{\mathrm{tX}}=\Phi_{\mathrm{tc}} /\left(1-\Phi_{\mathrm{ct}}\right)
$$

$\Phi_{\mathrm{tX}}$ values for $\mathrm{Cy}_{\mathrm{tr}} \mathrm{H}^{+}$, 1,2-diphenylpropene and Stilbene are 1.19, 0.96 and 0.77, respectively. In other words the $\mathrm{CyH}_{\text {tr }}^{+}$and $0.23 \%$ of 1,2-diphenylpropene ${ }_{t r} \mathrm{H}^{+}$disappear through isomerization. This means that the isomerization process of ${ }^{*} \mathrm{Cy}_{\mathrm{tr}} \mathrm{H}^{+}$represents the main channel of deactivation processes in water. At the photostationary state the proportion of cis to trance was found to be $64: 36$, also Steiner ${ }^{58}$ has noticed that there is an analogy in the structure of the protonated merocyanine dye and stilbene in their photochemical trans $\rightarrow$ cis isomerization reaction and in quantum yield. It was suggested that a phantom state $\mathrm{X}$, which is present in the protonated form at a $90^{\circ}$ twisted conformation of the excited state by which the deactivation process can occur to either trans or cis ground state.

\section{Thermal isomerization}

The kinetics of thermal cis $\rightarrow$ trans isomerization was investigated at different temperatures. The rate of disappearance of the cis form is described by a first order reaction with strong temperature dependence, equation (7):

$$
\frac{-d[M] c}{d t}=\mathrm{k}_{\mathrm{ct}}[\mathrm{M}]_{\mathrm{c}}
$$


The rate constant of the thermal reaction $\mathrm{k}_{\mathrm{ct}}$ was determined and evaluated in an Arrhenius plot to yield the activation energy, E and frequency factor, $\mathrm{k}_{\mathrm{o}}$. The Eyring theory was applied ${ }^{60}$ to calculate the activation parameters, enthalpy and entropy of activation. The following values were obtained:

$\mathrm{k}_{\mathrm{ct}}=1.00 \times 10^{-5} \mathrm{~s}^{-1}, \mathrm{E}_{\mathrm{a}}=28.15 \mathrm{kcal} / \mathrm{mol}, \mathrm{k}_{\mathrm{o}}=6.0 \times 10^{-15} \mathrm{~s}^{-1}, \Delta \mathrm{H}_{298}^{\#}=27.56 \mathrm{kcal} / \mathrm{mol}, \Delta \mathrm{G}_{298}^{\#}=$ $24.07 \mathrm{kcal} / \mathrm{mol}, \Delta \mathrm{S}^{\#}{ }_{298}=11.66 \mathrm{eu} / \mathrm{mol}$

From the foregoing results, as it is in good agreement with those reported for similar compounds. By comparing the molecular activity of $\mathrm{Cy}_{\mathrm{c}}$ with 1-methyl-4'- $(p-N, N-$ dimethylaminostyryl)pyridiniumiodid $\left(\mathrm{M}_{\mathrm{c}}\right)$ in aqueous solution, one can notice that the rate constant of $\mathrm{M}_{\mathrm{c}}$ reaction $\left(2.2 \times 10^{-4} \mathrm{~s}^{-1}\right)$ is higher than the case of $\mathrm{Cy}_{\mathrm{c}}$. Also, the activation energy $(26.12 \mathrm{kcal} / \mathrm{mol})$ and the positive value of entropy of activation $(10.39 \mathrm{eu} / \mathrm{mol})$ for $\mathrm{M}_{\mathrm{c}}$ reaction are slower than those for $\mathrm{Cy}_{\mathrm{c}}$ reaction ${ }^{56}$. The interaction of $\mathrm{Cy}_{\mathrm{c}}$ with water molecules is stronger than $\mathrm{M}_{\mathrm{c}}$ because its benzenoid structure has high stability as a result of its high ground state dipole moment and due to the formation hydrogen bonding by its phenoxy moiety with water molecules ${ }^{61-63}$.

\section{Effect of solvent on absorption and fluorescence spectra of $\mathrm{CyH}^{+}$}

To get information about the $\mathrm{CyH}^{+}$structure, its absorption band was measured in fourteen solvents of variable polarity. The band position changes according to the type of solvent (Table 2). Only a linear correlation was found between absorption energies and solvent hydrogen bond acceptor ability, $\beta^{64,65}$, as shown in Figure 5.

Table 2. Absorption band maximum $\lambda^{\mathrm{a}}{ }_{\max }(\mathrm{nm})$ of $\mathrm{CyH}^{+}$and solvent hydrogen bond acceptor ability, $\beta$, for different polar solvents

\begin{tabular}{cccccccc}
\hline Solvent & $\begin{array}{c}\lambda^{\mathrm{a}}{ }_{\max } \\
\mathrm{nm}\end{array}$ & $\begin{array}{c}\Delta \mathrm{E}_{\mathrm{a}} \\
\mathrm{kcal} / \mathrm{mol}\end{array}$ & $\beta$ & Solvent & $\begin{array}{c}\lambda_{\max }^{\mathrm{a}} \mathrm{nm} \\
\mathrm{nm}\end{array}$ & $\begin{array}{c}\Delta \mathrm{E}_{\mathrm{a}} \\
\mathrm{kcal} / \mathrm{mol}\end{array}$ & $\beta$ \\
\hline $\begin{array}{c}\text { Water } \\
\text { Ethylene }\end{array}$ & 338 & 84.615 & 0.18 & DMSO & 346 & 82.659 & 0.76 \\
glycol & 341 & 83.871 & 0.52 & DMF & 342 & 83.623 & 0.48 \\
Methanol & 343 & 83.382 & 0.66 & Acetone & 341 & 83.871 & 0.43 \\
Ethanol & 345 & 82.899 & 0.75 & Acetonitrile & 339 & 84.366 & 0.31 \\
1-Propanol & 347 & 82.421 & 0.9 & Ethyl acetate & 341 & 83.871 & 0.45 \\
1-Butanol & 347 & 82.184 & 0.88 & 1,4-Dioxane & 340 & 84.118 & 0.37 \\
2-Propanol & 347 & 82.421 & 0.84 & Cyclohexanol & 346 & 82.659 & 0.84 \\
\hline
\end{tabular}

The equation corresponding to the straight lines obtained is:

$$
\Delta \mathrm{E}_{\mathrm{a}}=85.36-3.35 \beta ; \mathrm{n}=14, \mathrm{r}=0.98
$$

Where $r$ is the correlation coefficient and $n$ is the number of solvents, as shown in Figure 5 Such linear equations indicating that studied compound the first electronic transition energy $\Delta \mathrm{E}_{\mathrm{a}}$ of $\mathrm{CyH}^{+}$is best correlates with the solvent proton acceptor ability. The electronic transition depends on the general environmental hydrogen bond effect while the environmental polarity has no effect. The negative sign of the correlation shows that the solvent ability of accepting proton decreases the absorption energy and can energetically destabilize the ground state of $\mathrm{CyH}^{+}$. Upon excitation the protonated molecule undergoes significant enhancement in its acidity and be sufficient to transfer the amine proton to the solvent during its radiation lifetime ${ }^{66}$. After the transfer event, the fully solvated proton is formed ${ }^{67,68}$ with a free energy of transfer to various solvents, $\Delta \mathrm{G}_{\mathrm{t}}{ }^{\mathrm{o}}$ Table 3 . 


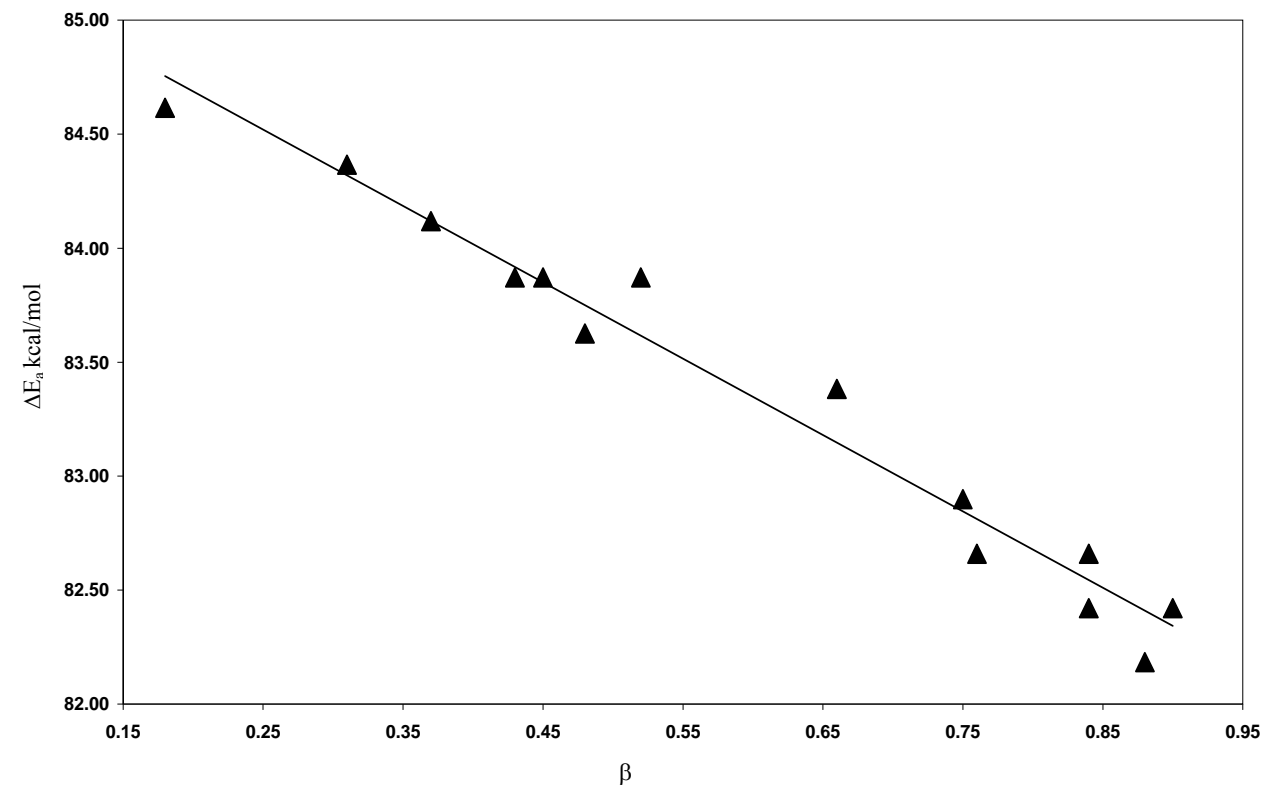

Figure 5. Correlation of absorption energy, $\Delta \mathrm{E}_{\mathrm{a}}$, of $\mathrm{CyH}^{+}$and hydrogen bond acceptor ability, $(\beta)$

Table 3. Fluorescence band maximum, $\lambda_{\max }^{\mathrm{f}}(\mathrm{nm})$, of $\mathrm{CyH}^{+}$and free energy of proton transfer to various solvents, $\Delta \mathrm{G}_{\mathrm{t}}^{\mathrm{o}}$, in $\mathrm{kcalmol}^{-1}$

\begin{tabular}{cccc}
\hline Solvent & $\begin{array}{c}\lambda_{\text {max }}^{\mathrm{f}} \\
\mathrm{nm}\end{array}$ & $\begin{array}{c}\Delta \mathrm{E}^{\mathrm{f}}{ }_{\max } \\
\mathrm{kcal} / \mathrm{mol}\end{array}$ & $\begin{array}{c}\Delta \mathrm{G}_{\mathrm{t}}{ }^{0} \\
\mathrm{kcal} / \mathrm{mol}\end{array}$ \\
\hline Methanol & 439 & 65.148 & 2.484 \\
Ethanol & 439 & 65.148 & 2.651 \\
Water & 441 & 64.853 & 0 \\
Ethylene glycol & 440 & 65.000 & 1.82 \\
DMSO & 446 & 64.126 & -4.636 \\
DMF & 445 & 64.269 & -4.299 \\
Acetonitrile & 433 & 66.051 & 11.082 \\
1,2-Dichloethane & 441 & 64.853 & 0.482 \\
\hline
\end{tabular}

A linear relationship was found between fluorescence energy and free energy for transferring the proton to the solvent as shown in Figure 6.

The equation corresponding to the straight lines obtained is:

$$
\Delta \mathrm{E}_{\text {max }}^{\mathrm{f}}(\mathrm{kcal})=64.78+0.12 \Delta \mathrm{G}_{\mathrm{t}}^{\mathrm{o}}, \mathrm{n}=8, \mathrm{r}=0.98
$$

Where $r$ is the correlation coefficient and $n$ is the number of solvents, Such linear equations indicate that aprotic solvents DMSO and DMF are better solvents for stabilizing $\mathrm{S}^{1}$ state than other solvents. In the excited state, the stability of the protonated benzenoid structure decreases with increase in the probability of the quinonoid structure by moving the negative charge from the aniline moiety to the pyridinium moiety passing through the bridge moiety. This enables aprotic solvents to be more active and effective to interact, causing more stabilization to $\mathrm{S}^{1}$ state. 


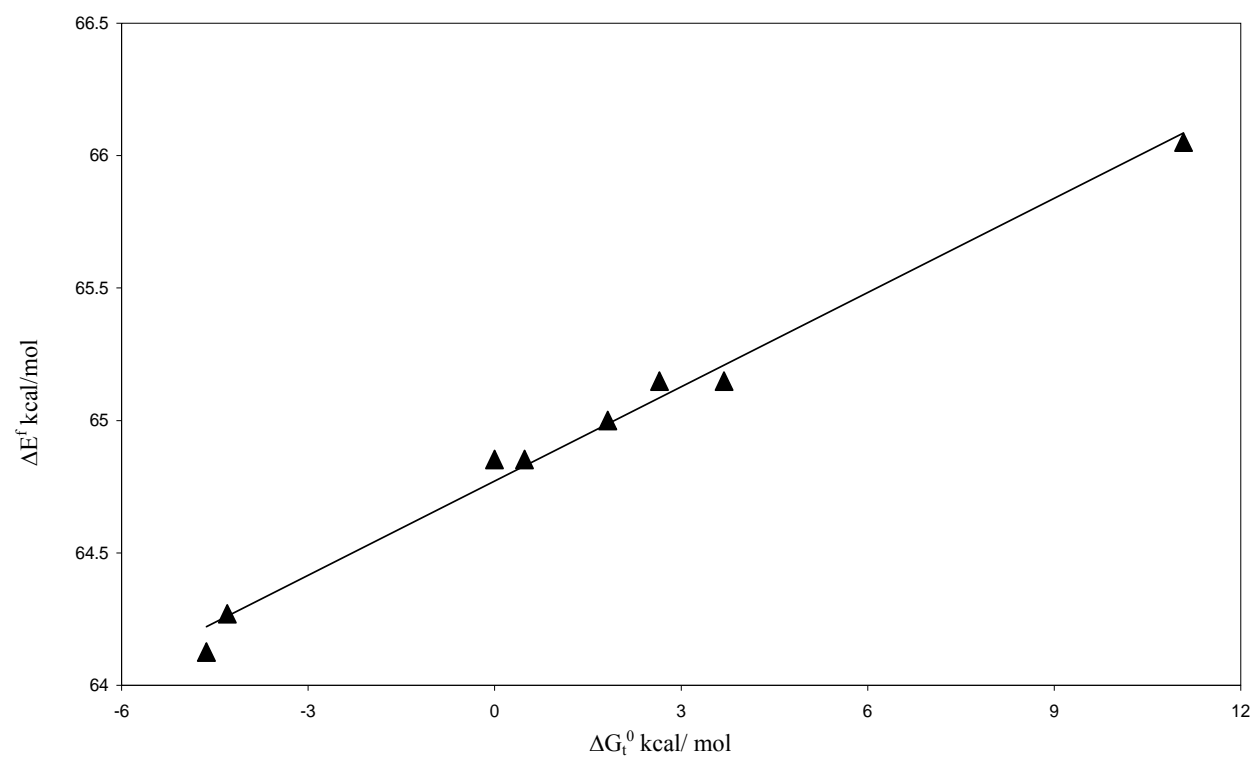

Figure 6. Correlation of fluorescence energy, $\Delta \mathrm{E}_{\max }^{\mathrm{f}}$, of $\mathrm{CyH}^{+}$and free energy of proton transfer, $\left(\Delta \mathrm{G}_{\mathrm{t}}{ }^{\mathrm{o}}\right)$

\section{References}

1. Gromov S P and Alfimov M V, Russ Chem Bull., 1997, 46(4), 611-636; DOI:10.1007/BF02495186

2. Fedorova O A, Fedorov Y V, Andryukhina E N, Gromov S P, Alfimov M V and Lapouyade R, Org Lett., 2003, 5(24), 4533-4535; DOI:10.1021/o1034848e

3. Alfimov M V, Gromov S P, Stanislavskii O B, Ushakov E N and Fedorova O A, Russ Chem Bull., 1993, 42(8), 1385-1389; DOI:10.1007/BF00699938

4. Vedernikov A I, Kuz'mina L G, Sazonov S K, Lobova N A, Loginov P S, Churakov A V, Strelenko Yu A, Howard J A K, Alfimov M V and Gromov S P, Russ Chem Bull Int Ed., 2007, 56, 1860-1883.

5. Gromov S P, Russ Chem Bull Int Ed., 2008, 57(7), 1325-1350.

6. Görner H and Gruen H, J Photochem., 1985, 28(3), 329-350; DOI:10.1016/00472670(85)85036-X

7. Barzykin A V, Fox M A, Ushakov E N, Stanislavsky O B, Gromov S P, Fedorova O A and Alfimov M V, J Am Chem Soc., 1992, 114(16), 6381-6385; DOI:10.1021/ja00$042 \mathrm{a} 013$

8. Ushakov E N, Gromov S P, Fedorova O A and Alfimov M V, Russ Chem Bull., 1997, 46(3), 463-471; DOI:10.1007/BF02495396

9. Gromov S P, Ushakov E N, Fedorova O A, Soldatenkova V A and Alfimov M V, Russ Chem Bull., 1997, 46(6), 1143-1148; DOI:10.1007/BF02496216

10. Atabekyan L S, Chibisov A K and Alfimov M V, High Energy Chem., 1997, 31(5), 344-348.

11. Fedorova O A, Chernikova E Yu, Fedorov Yu V, Gulakova E N, Peregudov A S, Lyssenko K A, Jonusauskas G J and Isaacs L, J Phys Chem B, 2009, 113, 10149-10158; DOI:10.1021/jp903289q

12. Altalbawy F M A and Alsherbini E A M, Asian J Chem., 2013, 25 (11), 6181-6185; DOI:10.14233/ajchem.2013.14305 
13. Watanabe S and Tani T, J Imag Sci Tech., 1995, 39, 81-85.

14. Serak S, Kovalev A and Agashkov A, Opt Commun., 2000, 181(4-6), 391-399; DOI:10.1016/S0030-4018(00)00767-7

15. Yoshida T, Zhang $\mathrm{J}$ and Komatsu D, Seiichi S, Hideki M, Thierry P, Daniel L, Torsten O, Derck S, Hirokazu T, Dieter W, Kazumasa F, Masaki M, Hidetoshi M and Hisao Y, Adv Funct Mater., 2009, 19(1), 17-43; DOI:10.1002/adfm.200700188

16. Li Q, Lin G L, Peng B X and Li Z X, Dyes Pigm., 1998, 38(4), 211-218; DOI:10.1016/S0143-7208(97)00088-0

17. Preston P N, Commercial Applications of Benzimidazoles, Benzimidazoles and Congeneric Tricyclic Compounds, part 2. New York: John Wiley, Ch. 10, 1980, 531.

18. Hong S, Yoon S S, Kang C and Suh M, Bull Korean Chem Soc., 2004, 25(3), 345346; DOI:10.5012/bkcs.2004.25.3.345

19. Roeland W D and Hans J T, Chem Biol., 2006, 13(6), 559-560; DOI:10.1016/j.chembiol.2006.06.006

20. Qian L, Yunkyung K, Joshua N, Amita K, Gus R R and Young-Hoon A, Chem Biol., 2006, 13(6), 615-623; DOI:10.1016/j.chembiol.2006.04.007

21. Jae W L, Michelle J, Gustavo R R and Young-Tae C, Chem Commun., 2003, 18521853; DOI:10.1039/B303960A

22. Kovalska V B, Kryvorotenko D V, Balanda A O, Losytskya M Y, Tokar V P and Yarmoluk S M, Dyes Pigm., 2005, 67(1), 47- 54; DOI:10.1016/j.dyepig.2004.10.007

23. Safavi A and Abdollahi H, Talanta, 2001, 53(5), 1001-1007; DOI:10.1016/S00399140(00)00591-9

24. Abdel-Halim S T and Awad M K, J Phys Chem., 1993, 97(13), 3160-3165; DOI:10.1021/j100115a017

25. Arden W and Fromherz P, J Electrochem Soc., 1980, 127(2), 370-378; DOI:10.1149/1.2129674

26. Kulbacka J, Pola A, Mosiadz D, Choromanska A, Nowak P, Kotulska M, Majkowski M, Hryniewicz-Jankowska A, Purzyc L and Saczko J, Biokhimiya (Moscow), 2011, 76(4), 473-479; DOI:10.1134/S0006297911040110

27. Inacker O, Kuhun H, Mo"bius D and Debuch G, Z Phys Chem Neue Folge, 1976, 101, 337-360.

28. Sieber F, Spivak J L and Sutctiffe A, Proc Natl Acad Sci USA, 1984, 81(23), 75847587.

29. Williams D J, Nonlinear Optical Properties of Organic and Polymeric Materials, ACS Symposium Series 233, American Chemical Society, Washington DC, 1983.

30. Campagnola P J and Low L M, Nature Biotech., 2003, 21(11), 1356-1360; DOI:10.1038/nbt894

31. Eldaly S A, Abdelkader M H, Issa R M and Elsherbini E A, Spectrochemica Acta A: Mole Biomoler Spectr., 2003, 59(2), 405-411; DOI:10.1016/S1386-1425(02)00182-8

32. Williams J L R, Webster S K and Van Allan J A, J Org Chem., 1961, 26 (12), 4893 4895; DOI:10.1021/jo01070a027

33. Williams J L R, Carlson J M, Reynolds G A and Adel R E, J. Org. Chem., 1963, 28(5), 1317-1320; DOI:10.1021/jo01040a040

34. Behera R K, Mishra A and Behera G B, Ind J Chem., 2000, 398, 783-786.

35. Mishra A, Behera R K, Behera P K, Mishra B K and Behera G B, Chem Rev., 2000, 100(6), 1973-2012; DOI:10.1021/cr990402t

36. Shawali A S, Zeid I F, Abdelkader M H, Elsherbini A A and Altalbawy F M A, $J$ Chin Chem Soc., 2001, 48(1), 65-72; DOI:10.1002/jccs.200100012

37. Shawali A S, Darwish E S S and Altalbawy F M A, Asian J Spectr., 2008, 12(2), 113-120. 
38. Shawali A S, Darwish E S S and Altalbawy F M A, Asian J Spectr., 2007, 11, 115-125.

39. Altalbawy F M A and Darwish E S S, Asian J Spectrosc., 2012, 16, 45-54.

40. Darwish E S, Mosselhi M A, Altalbawy F M and Saad H A, Molecules, 2011, 16(10), 8788-8802; DOI:10.3390/molecules 16108788

41. Shawali A S, Mosselhi M A, Altalbawy F M A, Farghaly T A and Tawfik N M, Tetrahedron, 2008, 64(23), 5524-5530; DOI:10.1016/j.tet.2008.03.096

42. Shawali A S, AbdelKader M H and Altalbawy F M A, Tetrahedron, 2002, 58(14), 2875-2880; DOI:10.1016/S0040-4020(02)00157-6

43. El-sherbini E A M, Abdel-Kader M H and Hamzah R Y, Colloids Surfaces A: Physicochem Eng Asp., 2001, 194(1-3), 133-142; DOI:10.1016/S0927-7757(01)00784-1

44. Melhuish W H, J. Phys. Chem., 1961, 65 (2), 229-235; DOI:10.1021/j100820a009

45. Murov S L, in: Hand book of Photochemistry, Marcel Dekker, New York, 1973.

46. Hatchard J G and Parker C A, Proc Roy Soc London, Ser A, 1956, 235, 518-536.

47. Gauglitz G, J Photochem., 1976, 5(1), 41-47; DOI:10.1016/0047-2670(76)85005-8

48. Gauglitz G and Hubig S, J Photochem., 1981, 15(3), 255-257; DOI:10.1016/00472670(81)87009-8

49. Gauglitz G, J Photochem., 1977, 7(5), 355-357; DOI:10.1016/0047-2670(77)80017-8

50. Abdel-Kader M H, Hamzah R Y and Abdel-Halim S T, J Photochem Photobiol., 1989, 50(5), 599-562; DOI:10.1111/j.1751-1097.1989.tb04314.x

51. Blanc J and Ross D L, J Phys Chem., 1968, 72(8), 2817-.2824; http://dx.doi.org/10.1021/j100854a022

52. Gegiou K A, Muszkat E and Fischer J, J Am Chem Soc., 1968, 90(15), 3907-3918; DOI:10.1021/ja01017a002

53. Herkstroeter G, Lamola A A and Hammond G S, J Am Chem Soc., 1964, 86, 45374540; DOI:10.1021/ja01075a005

54. Bartocci G, Bortolus P and Mazzucato U, J Phys Chem., 1973, 77(5), 605-610; DOI:10.1021/j100624a008

55. Steiner U, Abdel-Kader M H, Fisher P and Kramer H E, J Am. Chem Soc., 1978, 100(10), 3190-3197; DOI:10.1021/ja00478a039

56. Abdel-Halim S T, J Luminescence., 2011, 131(1), 30-35;

DOI:10.1016/j.jlumin.2010.08.022

57. Schulte-Frohlinde D, Blume H and Guesten H, J Phys Chem., 1962, 66, 2486, 2486.

58. Saltiel J, J Am Chem Soc., 1967, 89(4), 1036-1037; DOI:10.1021/ja00980a057

59. Ikeda N, Mataga N, Steiner U, Abdel-Kader M H, Chem Phys Lett., 1983, 95(1), 6671; DOI:10.1016/0009-2614(83)80811-2

60. Eyring H, Chem Rev., 1935, 17 (1), 65-77; DOI:10.1021/cr60056a006

61. Abdel-Halim S T, Abdel-Kader M H, Steiner U, J Phys Chem., 1988, 92, 4324-4328.

62. Abdel-Halim S T, J Chem Soc Faraday Trans., 1993, 89, 55-57; DOI: DOI:10.1039/FT9938900055

63. Abdel-Halim S T, Awad M K, J Mol Struct., 2005, 754(1-3), 16-24; DOI:10.1016/j.molstruc.2005.06.010

64. Kamlet M J, Abboud J L M, Abraham M H, Taft R W, J Org Chem., 1983, 48 (17), 2877-2887; DOI:10.1021/jo00165a018

65. S Sharafi, K A Muszkat, J. Am. Chem. Soc., 1971, 93(17), 4119-4125; DOI:10.1021/ja00746a004

66. Förster T, Z Elektrochem., 1950, 54, 531-535.

67. Marcus Y, Chem. Soc. Rev., 1993, 22, 409-416; DOI:10.1039/CS9932200409

68. Marcus Y, Ion Properties, Marcel Dekker, New York, 1997. 